\title{
Strategic Intelligence Teaching to Leverage Professional Success
}

\author{
Leonardo Guimarães Garcia \\ Professor, Faculty of Philosophy, Sciences and Literature, leonardogarcia@usp.br \\ University of Sao Paulo, 3900 Bandeirantes Avenue, Monte Alegre, Ribeirao Preto, Sao Paulo, Brazil
}

\begin{abstract}
$\mathrm{T}$

his research investigates whether undergraduate students believe that Competitive Intelligence (CI) teaching leads to an increase in their chances of professional success, regardless of whether they want a career in CI or not. It is an exploratory study, with an initial section on bibliographic research about CI teaching, followed by assessment of the perceptions of a class of six undergraduate students in a semester-long CI course. The data analyzed were: 1) teacher assessment; 2) students' self-assessment of the Degree of Learning (DL) in certain attributes of competence (i.e. pre-established knowledge, skills, and attitudes); 3) self-assessment of the Degree of importance (DI) for the same attributes in achieving the students' professional success (the reference for this part of the self-assessment was the individual career strategy, created by each student during the course). Based on the

DL results and the teacher's assessment, it was found that $\mathrm{CI}$ instruction was positive for all students. In addition, the self-assessment results indicated high DL and DI medians for almost all attributes, suggesting broad mastery of various attributes of competence considered important by students for their own professional success (despite the limitations in terms of statistical confirmation). The present work is original and relevant as it provides initial evidence that CI teaching can increase the chances of professional success for undergraduate students, even for those who do not wish to act as CI professionals. Furthermore, it is expected that the same benefits achieved by Brazilian students will also be available to CI students around the world since the appropriate adaptations were made, which have significant practical and social implications related to their employability and success.
\end{abstract}

\section{Keywords:}

competitive intelligence; professional success; teaching; competence; knowledge; skills; attitudes; career strategy; self-assessment

Citation: Guimarães Garcia L. (2020) Strategic Intelligence Teaching to Leverage Professional Success. Foresight and STI Governance, vol. 14, no 3, pp. 101-112.

DOI: $10.17323 / 2500-2597.2020 .3 .101 .112$ 
A round the world, the job market is becoming increasingly competitive. Good job opportunities require more and more skills, while the number of qualified people continually grows. In order to overcome this situation, professionals combine specialized training for specific contexts with the development of broader competences aiming at different situations - such as informational competence, related to obtaining and analyzing information [Horton, 2007; Julien et al., 2011], which is valued by the labor market due to the strong link between organizational performance and the effective use of information.

This competence is directly related to the practice of Competitive Intelligence (CI) [Ottonicar et al., 2018], whose distinctive feature is the production of high value-added information to support decision making [Fuld, 1995]. Due to this connection, it can be claimed that CI teaching can be a way to develop competences aimed at leading individuals to professional success. Since it is based on informational competence (and, therefore, on a more general idea of employability), this argument indicates the benefit that CI teaching can bring to everyone regardless of their areas of expertise or even their personal dreams of professional success.

On the other hand, there will be those for whom CI teaching will represent more than a general gain in employability. For CI professionals (or those aspiring to become them), CI teaching boosts their "right employability" - the one that represents a pathway towards the fulfillment of their specific professional desires and goals. This position is corroborated by alumni from institutions of excellence in CI teaching (such as those from the Academy of Competitive Intelligence $(\mathrm{ACI})^{1}$. For them, the competences developed in the CI course directly support their CI careers (and, of course, their expectations and dreams of professional success).

When we are talking about a CI discipline for undergraduate students, not all students are convinced of the merit of the pursuit of a CI career (in fact, most of them are more interested in increasing their employability by developing their information competence or even by adding an interesting new skill to their curriculum). For these, therefore, there is no direct connection between CI learning and the achievement of their own professional goals, as in the case of ACI alumni.

To achieve this kind of success, undergraduate students must master competences that are connected with their own expectations of success. From this observation, one question arises: do students who enroll in a university CI course, but do not wish to pursue a career in this area, achieve only a general gain in employability or do they actually achieve "right employ- ability"? Or, in other words: does a CI discipline have the power to leverage the true dreams of professional success for all of its students or only those who will pursue a career in $\mathrm{CI}$ ?

To investigate this challenge, the present work evaluated whether a CI undergraduate discipline could develop competence attributes (knowledge, abilities, and skills) indicated by the students as strongly connected with their professional success expectations. Next, we will present the architecture of the adopted CI teaching process, its implementation, and results whose analysis points to the veracity of the relationship between CI teaching and the increase in the chances for professional success of undergraduate students, in the opinion of the students themselves.

\section{Competitive Intelligence Teaching}

Attracting good professionals to the practice of CI is not a difficult task as this represents an exciting career and with many opportunities, especially for information professionals [Bexon et al., 2002]. On the other hand, it is still a challenge to find suitable training in the area, especially in some regions of the globe.

Due to certain cultural, academic-disciplinary barriers, CI university education is still limited. For this reason, and because of the strategic importance of $\mathrm{CI}$, even governments end up becoming involved in CI dissemination and education [Runtuwene et al., 2014; Calof, 2016]. However, class associations and some educational companies have been responsible for most of the challenge of training professionals in this area.

With regard to associations, SCIP (Strategic \& Competitive Intelligence Professionals) ${ }^{2}$ has been playing an essential role in training CI professionals, either through the courses it has led, the congresses and seminars it has promoted, or through publications about this subject it has disseminated [Miller, 2000]. Related to this point, SCIP has published many articles, editorials or columns (such as [Calof, 1999; Blenkhorn, Fleisher, 2003; Gilad, 2003; Hulnick, 2003; Kalb, 2003; Gutowski, 2007; McGonagle, 2007; Glitman, 2008]) through its main publication (Competitive Intelligence Magazine) aimed at CI teaching. In them, a wide range of subjects were dealt with, including the curriculum, teaching methods and techniques, and the influence of students' profiles upon course design, among others.

Some specialized companies have also made an essential contribution to CI training. Probably the most well-known example is that of the Academy of Competitive Intelligence, which for more than thirty years has been providing specialized CI education to over 10,000 professionals and high-level

Available at: https://academyci.com/alumni/, accessed 19.06.2020.

Available at: https://www.scip.org/, accessed 19.06.2020. 
decision makers from 71 countries around the world. Currently, they offer one of the most coveted professional CI certifications in the world in addition to in-house training, distance training, and individual development for executives.

Concerning universities, even considering the possibility of undergraduate or postgraduate courses entirely focused on CI, a good part of the CI teaching will occur through isolated disciplines offered to students with very different demands and profiles from those who seek the SCIP or ACI certifications. To begin with, not all students have a clear intention of pursuing a CI career. Several of them want to either enhance their curriculum or develop their informational competence to increase their employability. Furthermore, they are often very young and have no professional experience (as reported by [Blenkhorn, Fleisher, 2003]) and are unfamiliar with business terminology [Gutowski, 2007].

In order to adapt to the profile and demands of its public, university CI teaching has been applying its own solutions, some of which have been reported in the literature. Blenkhorn and Fleisher [Blenkhorn, Fleisher, 2003] highlight how much the use of projects as a tool for CI teaching are appreciated by undergraduates as it allows them to compare their knowledge with the real world and encourage them to overcome their competence gaps. Combining classes with hands-on activities is recommended in many papers [Miller, 1994; Bexon et al., 2002; Gilad, 2003; Fleisher, 2004; Zhou, Wang, 2013; Lemmer, 2015]. It was even possible to find a development initiative of a computational platform for undergraduate students aimed at CI teaching [Suyin et al., 2010].

Another constant in this literature is the development of competences. This subject is present in various papers [Calof, 1999; Kalb, 2003; Strauss, Du Toit, 2010; Zhou, Wang, 2013] and it represents the educators' conviction that effective teaching should impact the CI competences and its attributes (knowledge, skills, and attitudes). However, the same literature is restricted with respect to empirical studies that assess this impact. Such is the first contribution of this paper. The other contribution is related to the absence of studies on the real effectiveness of university CI courses on students' professional success. The literature on CI teaching at universities has focused almost exclusively on a restricted (and probably minority) audience: the students dedicated to having a career as a CI professional after college. But what about the others? Are our CI disciplines bringing them any closer to their idea of professional success? Such answers were not available in the literature.

\section{Development}

This research was conducted with six students pursuing a Bachelor's degree in Library and Information Science from the University of Sao Paulo (Ribeirao
Preto campus) enrolled in an elective course lasting 16 weeks, three hours per week in class and two hours per week (on average) of fieldwork outside the university. This course is focused exclusively on CI and has been offered every year since 2011. The six students correspond to the total number of students in the class, none of whom had previous training in CI.

Throughout the semester, students had weekly lectures, studied books and papers from international literature in the field [Fuld, 1995; Prescott, Miller, 2002; Sawka, 2002; Bensoussan, Fleisher, 2003; Tyson, 2006; Porter, 2008], as well as the content produced by the teacher for the classes. In parallel with the theoretical activities, the students undertook an individual CI project comprising several practical activities aimed at developing knowledge, skills, and attitudes related to CI performance. Each student selected and obtained permission to perform the project at a real organization (usually the one in which the student was doing his/her internship or was employed). Students, who could not identify an organization, were assigned one by the teacher.

Developing an individual project proposal was based on the Active Learning methodology that, in its various modalities, seeks to introduce flexibility and adaptability in different teaching contexts (including undergraduate courses) supporting innovation and promoting student-centered educational practices [Gleason et al., 2011; Lantis et al., 2019]. This theoretical framework was very important for the project design because it added consistency and completeness to the way in which it was planned, managed, and executed. Due to this theory, as well as the experience accumulated with the different CI classes over the last nine years, the role of the teacher and students in supporting the achievement of individual projects has been defined and refined.

The table below shows the two individual CI project macro activities carried out throughout the course with the teacher's feedback.

In parallel with the theoretical and practical activities already described, each student developed (under the teacher's supervision) their individual career strategy (i.e. a path to be taken to realize his or her dream of professional success).

On average, 30 minutes per week were devoted to discussing topics related to the construction of a career strategy: career purpose (the essence of professional success for each one); strengths and weaknesses (personal inventory of the most important internal factors to achieve desired success); career opportunities and threats (list of the most favorable and unfavorable external contingencies related to desired success); and the career strategy itself (textual or schematic representation - such as a mind map, for example - of the concrete path to achieve the desired success). In addition, a closed Facebook group was created to continue classroom discussions and allow students to exchange information and gain insights. 
Table 1. CI project macro-activities

\begin{tabular}{|c|c|}
\hline Macro-activities & Templates and Educational Support Tools \\
\hline $\begin{array}{l}\text { Diagnostic of the } \\
\text { organization selected } \\
\text { by the student }\end{array}$ & $\begin{array}{l}\text { Form filling (divided into two parts) concerning size, billing, type of economic activity, organization charts, number } \\
\text { of employees by functional area, main products/services, main suppliers, market segmentation and participation } \\
\text { by segment, mission, vision, values and strategic goals. A Pecha Kucha style presentation (https://www.pechakucha. } \\
\text { com/) was held to disseminate the results among the students. }\end{array}$ \\
\hline $\begin{array}{l}\text { Analysis of the } \\
\text { external environment } \\
\text { of the organization } \\
\text { selected by the } \\
\text { student }\end{array}$ & $\begin{array}{l}\text { This macro activity covered the study of the macro environment and the competitive environment, using Porter's } \\
\text { Five Forces and the STEEP Analysis (the latter according to the approach described in [Bensoussan, Fleisher, 2003]. } \\
\text { Several actions of this macro activity (especially information analysis) were partially carried out in the classroom, } \\
\text { with the direct support of the teacher. Another Pecha Kucha-style presentation was held at the end of this stage. }\end{array}$ \\
\hline \multicolumn{2}{|l|}{ Source: author. } \\
\hline
\end{tabular}

Teacher evaluation took place throughout the semester. From the macro-activities, task blocks were formed that were performed by the students weekly. The results of these tasks were consolidated into reports/deliverables (see Table 2), which were reviewed and returned to students for learning and corrections (most of the deliverables were inputs to subsequent tasks and therefore their correction was usually required). Thus, everyone could monitor their own progress and make adjustments to their study process and CI project if necessary.

Part of the assessment was accomplished at the end of the course, when students performed self-assessment using a questionnaire based on the attributes of competence (knowledge, skills, and attitudes). Self-assessment is widely recognized as a relevant approach to student learning measurement [Dochy et al., 1999; González de Sande, Godino-Llorente, 2014] and has been reported as a valuable option even in the context of CI teaching [Keiser, 2016].

The initial goal of self-assessment was to establish the Degree of Learning (DL) of each attribute of the competence indicated. To this end, it was emphasized that students should disregard their past mastery of attributes and focus their assessment exclusively on advancing those promoted by the course. In addition, as the quality of the assessment depended upon the students' understanding of the meaning of each attribute, the process of explaining the questionnaire also encompassed this prior clarification.

Assessing CI learning through a list of attributes of competence entails the recognition that one of the aims of teaching is to develop the competences necessary for successful CI practice. From this conception comes an essential advantage, that is, to keep the focus of the educational process on the students' competences. However, other difficulties appear, such as choosing how competences will be developed and evaluated, or even choosing which attributes of competence are to be considered in the process.

Regarding the development and evaluation of the competences, the approach adopted in the course has already been described: in the case of development, the union between theory and practice mediated by Active Learning as well as assessment, correction, and feedback throughout the semester (Table 2) plus self-assessment at the end of the course. Especially in the case of evaluation, using both strategies contributes to increasing the reliability of the conclusions. Moreover, it should be remembered that this topic is controversial and there is no evaluative strategy that is considered definitive, especially those aimed at assessing the attributes of competence [Rychen, Ferrer, 2004].

Concerning the choice of attributes, it was based on the main activities of the intelligence cycle and the most recurrent competences in the literature [Calof, 1999; Kalb, 2003; Strauss, Du Toit, 2010; Zhou, Wang, 2013]. In short, an attempt was made to make the most universal selection of attributes possible, despite the understanding that the practice of $\mathrm{CI}$ is contextual, potentially conditioned even by the region of the globe in which it is practiced [Blenkhorn, Fleisher, 2010]. In addition, as it is an educational process directed at students with no experience in the area, basic knowledge, skills, and attitudes that could be learned by beginners were selected. Although this is not a validated list of attributes, the selected ones have the potential to encompass different formative situations - including within companies - aimed at individuals with no CI practice or in its early stages.

Having assessed DL, a new self-assessment questionnaire based on the same attributes was used for students to indicate the Degree of Importance (DI) of each attribute for the achievement of their own career strategy. Since the professional success desired by each student is represented by their career strategy, the power of DI is to point out the importance of attributes for achieving that success. It follows that the larger the group of attributes with high DL and DI simultaneously, the greater the course's contribution to increasing students' chances of professional success.

Thus, after a self-assessment of DL and DI, the group of attributes of competence with high DL (i.e. attributes highly developed as a result of CI learning promoted by the course) was compared with those with high DI (i.e. those pointed out as highly important for the achievement of the professional success desired by the students). This comparison showed the intersection between these groups, formed by the at- 
Table 2. Teacher deliverables assessment

\begin{tabular}{|c|c|c|c|c|c|c|}
\hline \multirow{2}{*}{ Deliverables (\% of the total score) } & \multicolumn{6}{|c|}{ Students' Scores } \\
\hline & $\# 1$ & $\# 2$ & \#3 & \#4 & \#5 & \#6 \\
\hline Internal Diagnostic Report - Part One (10\%) & 8.0 & 6.0 & 7.0 & 8.0 & 9.0 & 6.0 \\
\hline Internal Diagnostic Presentation - Pecha Kucha (5\%) & 8.0 & 7.0 & 9.0 & 6.0 & 10.0 & 8.0 \\
\hline External Diagnostic Report - Information Sources (5\%) & 6.0 & 8.0 & 8.5 & 7.0 & 9.0 & 9.0 \\
\hline $\begin{array}{l}\text { External Diagnostic Report - Industry Information Collection / Porter's Five } \\
\text { Forces }(7,5 \%)\end{array}$ & 7.0 & 7.5 & 5.5 & 7.0 & 9.0 & 8.5 \\
\hline $\begin{array}{l}\text { External Diagnostic Report - Macro Environmental Information Collection / } \\
\text { STEEP Analysis (see Bensoussan and Fleisher, 2003) (7,5\%) }\end{array}$ & 8.0 & 7.0 & 7.0 & 5.0 & 10.0 & 4.5 \\
\hline External Diagnostic Report - Analysis Matrix of Collected Information (20\%) & 7.0 & 8.5 & 6.5 & 7.5 & 9.0 & 7.0 \\
\hline External Diagnostic Report - Complete (10\%) & 7.0 & 9.0 & 7.0 & 7.0 & 9.0 & 6.0 \\
\hline External Diagnostic Presentation - Pecha Kucha (5\%) & 7.5 & 9.0 & 6.0 & 7.5 & 10.0 & 7.0 \\
\hline Individual Career Strategy Report (15\%) & 8.5 & 10.0 & 7.5 & 8.5 & 9.0 & 8.0 \\
\hline $\begin{array}{ll}\text { FINAL SCORE } \\
\end{array}$ & 7.5 & 8.1 & 7.1 & 7.5 & 9.2 & 7.2 \\
\hline
\end{tabular}

tributes that had both high DL and high DI. The size and prevalence of the attributes of this intersection compared to the total allowed us to infer the influence of CI teaching upon students' chances of success

\section{Results}

This investigation into the relationship between students' learning and their chances of professional success assumes that they were able to achieve a good level of learning during the course. Two actions were fundamental to this objective: 1) the weekly review of students' individual CI project deliverables; 2) classroom discussions about these deliverables. This permanent feedback structure allowed students to understand their real learning level and, when necessary, to adjust their efforts. Besides, a proper understanding of their real learning would prepare students for a more conscious and realistic DL self-assessment.

In order to establish a reference for the analysis of the DL results, the teacher's deliverables assessment is presented in Table 2. The score ranged from zero (task completely incorrect or not completed on time) to 10 (task fully performed and with great practical results compared to what is expected for a student). The good overall performance of the class can be observed, something supported by using Active Learning and the small number of students in the class (only six). This positive learning outcome for the students is corroborated by the on-site observation of the teacher, which occurred mainly through the systematic feedback given to the students regarding their practical activities.

This result indicates a high probability that various competence attributes have high DL, since both express the same variable: student learning. Table 2 is particularly relevant because, despite the vast literature on self-assessment and its advantages (as in [Dochy et al., 1999; González de Sande, GodinoLlorente, 2014], even for CI [Keiser, 2016], there is always concern about its effectiveness - especially in a study with few subjects. The teacher's assessment attesting to the quality of learning serves to dispel this fear.

Tables 3, 4, and 5 show the attributes of competence (knowledge, skills, and attitudes) that make up the course and were considered by students in their DL and DI self-assessment, their DL and DI levels indicated by the students, the median of these indications (column "MED."), the number of occurrences of DL and DI below the value considered the minimum threshold for stating that the DL and DI were high (column " $x$ "), the sum of all occurrences below and above this minimum value (column" $\mathrm{n}$ "), and the critical value for the statistical significance a (twotailed) of the median of DL and DI (column "C.V.").

The final four columns of DL and DI can be used to carry out a nonparametric statistical test called the Sign Test (see [Sprent, Smeeton, 2001]), used to estimate the significance of hypotheses for studies such as the present study (i.e., exploratory, without predefined statistical parameters that use the Likert Scale and have a small number of respondents).

The columns "Degree of Learning - DL" were numbered from 1 to 5 represent the number of students who indicated each of these five DL levels (Likert Scale): $1-$ No learning or very little learning; $2-$ Little/insufficient learning; 3 - Good/adequate learning; 4 - Very good learning; and 5 - Excellent learning beyond expectations. For DL, a value that exceeds Level 3 was considered high.

Likewise, the columns "Degree of Importance - DI" represent the number for the five adopted DI levels (Likert Scale): 1 - No importance (or very slight importance); 2 - Little importance; 3 - Good im- 
portance; 4 - Great importance; and 5 - Essential/ Indispensable (the attribute is a critical success factor for professional success). For DI, a value that exceeds level 3 was considered high.

\section{Discussion}

Before discussing the results, it is important to point out that this study was based not on traditional indicators of professional success (such as salary increases, promotions, etc.), but on students' perception of their own success. We know that professional success is a multifaceted, circumstantial, and subjective concept. Therefore, it would not be possible to establish a definition in which all fit. Our choice in this research was to equip each student with the ability to: 1 ) establish their own vision of professional success; 2 ) represent it as an individual career strategy; and 3) evaluate the DI using this personal reference. Thus, the DI assessment, by pointing out the attributes of competence that increase one's chances of following a career strategy, indicates the attributes that increase the chances of professional success.

Another important issue is related to DL. Although this measure is, in some way, an expression of the quality of teaching, the instructions given to students before the DL evaluation and their feedback made it clear to everyone that the focus of the evaluation should be on the learning accumulated throughout the semester, and not the means for that learning (i.e., the discipline). In this context, the importance of teacher evaluations is reiterated (Table 2) as evidence of good student learning, which not only generates an expectation of high DL values, but also corroborates them (if they are high), as they will coincide with the conclusion reached by the teacher after monitoring and correcting students' work throughout the semester. Thus, the DL's perhaps restricted reliability due to the assessment method and the number of respondents is offset by the professor's assessment.

Considering that this research aims to determine whether a CI discipline has the power to leverage the true dreams of professional success of all its students or only those who will pursue a career in CI, first of all it is necessary to locate among the students those determined to become CI professionals, separate them from the others and analyze the DL and DI results for these two groups of students separately. To perform this separation, Table 6 was made, which presents a summary of students' dreams and goals for their professional success extracted from the individual career strategies developed by each student throughout the course.

In line with the previously described possibility, the table shows that none of the students expressed a clear desire to build a career in CI. Two of them are somehow connected to the informational job market due to the intention of developing technological solutions for the provision of services (students 2 and 6). Another one reports the desire to open a local super- market (student 5), two others to pursue a master's degree (students 1 and 4), one to work preferably in the financial market (student 3 ), and another pointed out the desire to pursue a military career as a public servant (student 2). The consequence of this discovery is that, for the analysis of DL and DI, it will not be necessary to separate the students into two groups.

Another interesting conclusion from this table is that, although the students are from the same undergraduate course, there is a wide range of ideals among them. From the point of view of the Library and Information Science teacher, the finding that students mostly want to work on different job markets than the informational one can be surprising. However, from the research perspective, diversity rules out the possibility that the results of DI are only a reflection of the connection between the informational job market (the expected target for these students) and the competence attributes developed by CI teaching (linked to informational competence and therefore to the informational job market).

This evidence indicates that, by assigning a DI value to each attribute, students evaluated this variable without the bias that would be present if their main interest was to work on the informational job market. On the contrary, the assessment was based on the students' authentic dreams of professional success spread across different labor markets.

As already discussed, the fulfillment of the research objective depends upon identifying attributes with high DL and DI simultaneously. Therefore, it was necessary to indicate a criterion that established whether a value of DL and DI was high or not. In this study, DL was considered high when most of the students in the course $-50 \%$ or more - assigned either the degree of learning "very good" (Level 4) or "excellent/beyond expectations" (Level 5) to the attribute, in other words, any of the levels greater than 3 . The same was true for DI, which was considered high whenever most of the students rated the attribute as either of "great importance" (Level 4) or "essential/ indispensable to their professional success" (Level 5).

In statistical terms, this criterion means that DL or DI will be considered adequate if the median value of the competence attribute is greater than 3 . The median was chosen instead of the mean because it is a study whose distribution curve is unknown. Tables 3,4 , and 5 show the median values with the label "MED."

By observing the results exclusively from the perspective of the median, it can be said that all competence attributes reached the minimum value (i.e., 3 ) both for DL and DI. However, an analysis of the tables reveals that the attributes "K6", "S5", and " $S 9$ " have discrepant behavior with few evaluations above 3 and many below this value, when compared to the other attributes.

Even disregarding these three attributes, the results indicate that for most students, there was very good 
Table 3. Degree of Learning (DL) and Degree of Importance (DI) of Knowledge Attributes - Student Self-Assessment

\begin{tabular}{|c|c|c|c|c|c|c|c|c|c|c|c|c|c|c|c|c|c|c|c|}
\hline \multirow{2}{*}{ \# } & \multirow{2}{*}{$\begin{array}{l}\text { Assessed } \\
\text { Knowledge }\end{array}$} & \multicolumn{9}{|c|}{ Degree of Learning - DL } & \multicolumn{9}{|c|}{ Degree of Importance - DI } \\
\hline & & 1 & 2 & 3 & 4 & 5 & MED. & $\mathbf{x}$ & $\mathbf{n}$ & C.V. & 1 & 2 & 3 & 4 & 5 & MED. & $\mathbf{x}$ & $\mathbf{n}$ & C.V. \\
\hline K1 & $\begin{array}{l}\text { What is Competitive } \\
\text { Intelligence }(\mathrm{CI}) \text { ? }\end{array}$ & 0 & 0 & 1 & 1 & 4 & 5 & 0 & 5 & $0(\alpha=10 \%)$ & 0 & 0 & 2 & 2 & 2 & 4 & 0 & 4 & - \\
\hline $\mathrm{K} 2$ & $\begin{array}{l}\text { CI needs: what it is } \\
\text { and how to do it }\end{array}$ & 0 & 0 & 1 & 4 & 1 & 4 & 0 & 5 & $0(\alpha=10 \%)$ & 0 & 1 & 1 & 2 & 2 & 4 & 1 & 5 & - \\
\hline $\mathrm{K} 3$ & $\begin{array}{l}\text { CI planning: what it } \\
\text { is and how to do it }\end{array}$ & 0 & 0 & 2 & 1 & 3 & 4.5 & 0 & 4 & - & 0 & 0 & 1 & 4 & 1 & 4 & 0 & 5 & $0(\alpha=10 \%)$ \\
\hline K4 & $\begin{array}{l}\text { CI collection: what it } \\
\text { is and how to do it }\end{array}$ & 0 & 1 & 0 & 2 & 3 & 4.5 & 1 & 5 & - & 0 & 0 & 1 & 4 & 1 & 4 & 0 & 5 & $0(\alpha=10 \%)$ \\
\hline K5 & $\begin{array}{l}\text { CI analysis: what it } \\
\text { is and how to do it }\end{array}$ & 0 & 0 & 0 & 4 & 2 & 4 & 0 & 6 & $0(\alpha=5 \%)$ & 0 & 0 & 1 & 4 & 1 & 4 & 0 & 5 & $0(\alpha=5 \%)$ \\
\hline K6 & $\begin{array}{l}\text { CI dissemination: } \\
\text { what it is and how } \\
\text { to do it }\end{array}$ & 0 & 1 & 3 & 1 & 1 & 3 & 1 & 3 & - & 0 & 0 & 1 & 3 & 2 & 4 & 0 & 5 & $0(\alpha=10 \%)$ \\
\hline K7 & $\begin{array}{l}\text { CI assessment: what } \\
\text { it is and how to do it }\end{array}$ & 0 & 0 & 2 & 2 & 2 & 4 & 0 & 4 & - & 0 & 1 & 1 & 2 & 2 & 4 & 1 & 5 & - \\
\hline K8 & $\begin{array}{l}\text { The internal } \\
\text { environment of } \\
\text { organizations: what } \\
\text { it is and its main } \\
\text { aspects }\end{array}$ & 0 & 0 & 1 & 2 & 3 & 4.5 & 0 & 5 & $0(\alpha=10 \%)$ & 0 & 0 & 1 & 4 & 1 & 4 & 0 & 5 & $0(\alpha=10 \%)$ \\
\hline K9 & $\begin{array}{l}\text { The external } \\
\text { environment of } \\
\text { organizations: what } \\
\text { it is and its main } \\
\text { aspects }\end{array}$ & 0 & 0 & 1 & 1 & 4 & 5 & 0 & 5 & $0(\alpha=10 \%)$ & 0 & 0 & 1 & 3 & 2 & 4 & 0 & 5 & $0(\alpha=10 \%)$ \\
\hline & AVERAGE (\%) & 0 & 5.6 & 16.6 & 30.6 & 47.2 & - & - & - & - & 0 & 7.0 & 16.6 & 48.6 & 27.8 & - & - & - & - \\
\hline
\end{tabular}

or excellent learning in various attributes that they considered to be very important or essential to their professional success. This represents the best combination of course efficiency (high student learning) and effectiveness (optimal future student benefit expectations).

The table below details the intersection between high DL and DI (except for "K6", "S5", and "S9"). Note that there is DL ranging from the simple majority $(50 \%$ of students) to the totality (as in the case of "K5" for which all students reported very good or excellent learning). However, most are in the range of the simple majority and the vast majority (83.3\%). In the case of DI, the attributes were concentrated in a range between $66.7 \%$ and $83.3 \%$, indicating that the students evaluated the DI more positively than the DL. This may be due to the fact that the choice of attributes to be evaluated was particularly consistent with the students' career trajectories.

The table above also identifies the four attributes of knowledge (K4, K5, K8, and K9) and the three attributes of skill (S3, S7, and S8) with the best combination of learning and importance for success. This indicates that, for this particular class of students, these are the most strategic attributes. It is clear that the search for success is individual, therefore what matters most to each student are the attributes indicated by themselves as strategic. However, identifying the set of the most strategic attributes for each class may, over time, allow for an association to develop between the attributes and the profile of each class.

Considering that the focus of this study was to shed light on the connection between the competence attributes developed in an optional university CI course and the professional success idealized by the students, we believe that the analysis of the median represents the most adequate general indication of the success of the work. This is because having a small number of students is natural for this research context given the heterogeneous interests of undergraduate students at our university. Certainly, other scenarios for university teaching of CI may arise and ensure a larger audience, but in the same way, small classes will be typical. It follows that much empirical research of this type (as well as the current study) will have an intrinsic limitation on the statistical significance of its results. The data in Tables 3, 4, and 5 make this clear: when submitting the attributes, previously endorsed by the median result, to the nonparametric Sign Test, we see that:

- in terms of DL, only one attribute reached 5\% significance, eight reached $10 \%$ significance, and the others either did not allow any inference (because it is not possible to determine a critical region in the standard table of significance values) or were rejected; 
Table 4. Degree of Learning (DL) and Degree of Importance (DI) of Skills Attributes Student Self-Assessment

\begin{tabular}{|c|c|c|c|c|c|c|c|c|c|c|c|c|c|c|c|c|c|c|c|}
\hline \multirow{2}{*}{$\#$} & \multirow{2}{*}{ Assessed Skills } & \multicolumn{9}{|c|}{ Degree of Learning - DL } & \multicolumn{9}{|c|}{ Degree of Importance - DI } \\
\hline & & 1 & 2 & 3 & 4 & 5 & MED. & $\mathbf{x}$ & $\mathbf{n}$ & C.V. & 1 & 2 & 3 & 4 & 5 & MED. & $\mathbf{x}$ & $\mathbf{n}$ & C.V. \\
\hline S1 & $\begin{array}{l}\text { Collect information } \\
\text { from people and } \\
\text { documents }\end{array}$ & 0 & 1 & 2 & 1 & 2 & 3.5 & 1 & 4 & - & 0 & 1 & 1 & 0 & 4 & 5 & 1 & 5 & - \\
\hline S2 & $\begin{array}{l}\text { Assess the reliability } \\
\text { of data and } \\
\text { information }\end{array}$ & 0 & 1 & 2 & 1 & 2 & 3.5 & 1 & 4 & - & 0 & 0 & 1 & 2 & 3 & 4.5 & 0 & 5 & $0(\alpha=10 \%)$ \\
\hline S3 & $\begin{array}{l}\text { Classify and treat } \\
\text { information collected } \\
\text { for CI analysis }\end{array}$ & 0 & 0 & 1 & 3 & 2 & 4 & o & 5 & $0(\alpha=10 \%)$ & 0 & 0 & 1 & 3 & 2 & 4 & 0 & 5 & $0(\alpha=10 \%)$ \\
\hline S4 & $\begin{array}{l}\text { Create conclusions } \\
\text { and arguments with } \\
\text { logic and traceability }\end{array}$ & 0 & 1 & 0 & 4 & 1 & 4 & 1 & 6 & - & 0 & 1 & 1 & 2 & 2 & 4 & 1 & 5 & - \\
\hline S5 & $\begin{array}{l}\text { Establish implications } \\
\text { after understanding } \\
\text { context through CI } \\
\text { analysis }\end{array}$ & 0 & 2 & 2 & 0 & 2 & 3 & 2 & 4 & - & 0 & 1 & 1 & 3 & 1 & 4 & 1 & 5 & - \\
\hline S6 & \begin{tabular}{|l|} 
Make \\
recommendations \\
based on implications \\
derived from CI \\
analysis
\end{tabular} & 0 & 1 & 2 & 1 & 2 & 3.5 & 1 & 4 & - & 0 & 1 & 1 & 4 & 0 & 4 & 1 & 5 & - \\
\hline S7 & $\begin{array}{l}\text { Describe the internal } \\
\text { environment of } \\
\text { organizations }\end{array}$ & 0 & 0 & 1 & 3 & 2 & 4 & 0 & 5 & $0(\alpha=10 \%)$ & 0 & 0 & 1 & 1 & 4 & 5 & 0 & 5 & $0(\alpha=10 \%)$ \\
\hline S8 & $\begin{array}{l}\text { Describe the external } \\
\text { environment of } \\
\text { organizations }\end{array}$ & 0 & 0 & 1 & 2 & 3 & 4.5 & 0 & 5 & $0(\alpha=10 \%)$ & 0 & 0 & 1 & 3 & 2 & 4 & 0 & 5 & $0(\alpha=10 \%)$ \\
\hline S9 & $\begin{array}{l}\text { Perceive the true } \\
\text { strategy/strategic } \\
\text { goals of organizations }\end{array}$ & 0 & 1 & 3 & 1 & 1 & 3 & 1 & 3 & - & 0 & 1 & 1 & 2 & 2 & 4 & 1 & 5 & - \\
\hline S10 & $\begin{array}{l}\text { Extract from CI } \\
\text { results, ideas and } \\
\text { opportunities to } \\
\text { leverage the success of } \\
\text { organizations }\end{array}$ & 0 & 0 & 2 & 3 & 1 & 4 & 0 & 5 & $0(\alpha=10 \%)$ & 0 & 0 & 2 & 2 & 2 & 4 & 0 & 4 & - \\
\hline & AVERAGE (\%) & 0 & 12.8 & 26.9 & 29.5 & 30.8 & - & - & - & - & $\mathbf{0}$ & 7.7 & 21.8 & 33.3 & 37.1 & - & - & - & - \\
\hline
\end{tabular}

- in terms of DI, one attribute reached 5\% significance, 10 reached $10 \%$ significance, and the others did not allow inference or were rejected;

- only six attributes had simultaneously high values of DL and DI with statistical significance one of them ("K5") with $5 \%$ significance and the others ("K8", "K9", "S3", "S7", and "S8") with $10 \%$ significance (the similarity between this list of attributes and the one indicated in Table 7 stands out as being the most representative attributes of the class).

This limitation in terms of statistical significance would indicate, for many studies, sampling and/or experimental deficiencies. However, for this study this result stems from an intrinsic feature of the research -one representation of the reality at numerous universities that offer CI optional subjects - that is, the small number of students enrolled. Still, we believe that the results serve their fundamental purpose, despite the generalization issues: adding insights and new possibilities to the existing literature. By not drawing any definitive conclusions, this study bypasses the statistical limitations by pointing out a new connection between CI teaching and the expectations of genuine professional success among undergraduate students.

\section{Conclusions}

Do the students who enroll in a university CI course but who do not aspire to pursuing a career in this area only achieve that more general employability or do they find the "right employability" thanks to the course? Or, in other words: does a CI discipline have the power to leverage the true dreams of professional success for all of its students or only those who will pursue a career in CI? To answer these questions, the present work investigated whether a CI undergraduate discipline could develop competence attributes (knowledge, abilities, and skills) indicated by the students as strongly connected with their professional success expectations.

Six university students participated in an CI course and at the same time developed their individual career strategies. At the end of the teaching process and 
Table 5. Degree of Learning (DL) and Degree of Importance (DI) of Attitudes Attributes - Student Self-Assessment

\begin{tabular}{|c|c|c|c|c|c|c|c|c|c|c|c|c|c|c|c|c|c|c|c|}
\hline \multirow{2}{*}{$\#$} & \multirow{2}{*}{ Assessed Attitudes } & \multicolumn{9}{|c|}{ Degree of Learning - DL } & \multicolumn{9}{|c|}{ Degree of Importance - DI } \\
\hline & & 1 & 2 & 3 & 4 & 5 & MED. & $\mathbf{x}$ & $\mathbf{n}$ & C.V. & 1 & 2 & 3 & 4 & 5 & MED. & $\mathbf{x}$ & $\mathbf{n}$ & C.V. \\
\hline A1 & $\begin{array}{l}\text { Motivation to } \\
\text { understand the internal } \\
\text { environment of } \\
\text { organizations }\end{array}$ & 0 & 0 & 3 & 1 & 2 & 3.5 & 0 & 3 & - & 1 & 1 & 0 & 2 & 2 & 4 & 2 & 6 & - \\
\hline A2 & $\begin{array}{l}\text { Motivation to } \\
\text { understand the external } \\
\text { environment of } \\
\text { organizations }\end{array}$ & 0 & 0 & 2 & 3 & 1 & 4 & 0 & 4 & - & 1 & 0 & 1 & 3 & 1 & 4 & 1 & 5 & - \\
\hline A3 & $\begin{array}{l}\text { Analytical thinking } \\
\text { about organizational } \\
\text { issues }\end{array}$ & 0 & 0 & 2 & 3 & 1 & 4 & 0 & 4 & - & 0 & 1 & 1 & 1 & 3 & 4.5 & 1 & 5 & - \\
\hline A4 & $\begin{array}{l}\text { Strategic look at key } \\
\text { organizational issues }\end{array}$ & 0 & 0 & 3 & 2 & 1 & 3.5 & 0 & 3 & - & 0 & 1 & 1 & 0 & 4 & 5 & 1 & 5 & - \\
\hline A5 & \begin{tabular}{|l} 
Critical sense of \\
decisions and/or \\
strategic actions of \\
organizations
\end{tabular} & 0 & 1 & 2 & 2 & 1 & 3.5 & 1 & 4 & - & 0 & 1 & 0 & 3 & 2 & 4 & 1 & 6 & - \\
\hline A6 & $\begin{array}{l}\text { Discernment to discuss } \\
\text { strategic issues of } \\
\text { organizations }\end{array}$ & 0 & 1 & 2 & 2 & 1 & 3.5 & 1 & 4 & - & 0 & 1 & 1 & 1 & 3 & 4.5 & 1 & 5 & - \\
\hline A7 & $\begin{array}{l}\text { Confidence to } \\
\text { participate in decisions } \\
\text { and/or strategic actions } \\
\text { of organizations }\end{array}$ & 0 & 1 & 2 & 3 & 0 & 3.5 & 1 & 4 & - & 0 & 0 & 2 & 1 & 3 & 4.5 & 0 & 4 & - \\
\hline A8 & \begin{tabular}{|l|} 
Confidence and \\
discernment to \\
contribute to the success \\
of organizations
\end{tabular} & 0 & 2 & 1 & 2 & 1 & 3.5 & 2 & 5 & - & 0 & 0 & 1 & 3 & 2 & 4 & 0 & 5 & $\begin{array}{c}0 \\
(\alpha=10 \%)\end{array}$ \\
\hline & AVERAGE (\%) & 0 & 11.7 & 28.3 & 36.7 & 23.4 & - & - & - & - & 3.3 & 8.3 & 11.6 & 26.6 & 50.0 & - & - & - & - \\
\hline
\end{tabular}

the creation of individual career strategies, students used a questionnaire based on attributes of competence related to CI to self-evaluate 1) the Degree of Learning (DL) of each attribute from the teaching process and 2) the Degree of Importance (DI) of each attribute for fulfilling their own career strategy.

Using the results of DL in association with the teacher assessment of the students' deliverables (Table 2), it was possible to establish that CI learning was positive for all students. On the other hand, self-evaluation showed high DL and DI medians for almost all attributes. The union of these results indicates that the teaching process was able to promote effective CI learning in various attributes of competence considered important by students for their professional success, which indicates that CI teaching increases individuals' chances of professional success.

The small number of students limits the generalization of these findings, in addition to the fact that the group is homogeneous in several characteristics (most are young with no professional experience). Besides that, the development of the students' individual career strategies in parallel with the CI teaching continually sparked a debate in the classroom about how CI could support the success of each one. The result was a strong interaction between the researcher and the research object and the need for research itself to be framed as active research, since it is a method aimed at empirical research in which researchers and participants are involved in a cooperative or participatory way.

All of these arguments make the traditional generalization unfeasible. On the other hand, for different sciences such as Administration, Information Science and Education, an exploratory study that is not generalizable and even carried out with a small number of participants may be relevant, given its capacity to add a new element to the existing literature and increase the researcher's familiarity with a new or complex problem. Recognizing their own nature, exploratory studies with small populations do not claim to present definitive conclusions. Rather, they try to present new constructs (as is the case with this study, which seeks to establish a relationship in the literature between the university CI teaching and the leverage of the students' professional success).

As already stated, it is likely that both the attributes developed by CI courses and the students' professional dreams vary according to the country and its socio-professional context. CI teachers in their universities establish their pedagogical project and their tools for assessing students' learning in those competence attributes upon which your courses were based 


\section{Table 6. Dreams and goals that characterize the students' professional success}

\begin{tabular}{|c|c|}
\hline Student & Dreams and goals \\
\hline$\# 1$ & $\begin{array}{l}\text { In the beginning, it is having a very comfortable salary in the short term, enabling me to make a living without needing } \\
\text { anyone. This means growing professionally and generating a meaningful network of contacts to prevail upon and be active } \\
\text { with my business on the job market. In the near future, to be able to set up my own company and be influential in the segment } \\
\text { I want to operate in, which is the technological sector. Create a } 100 \% \text { digital and multichannel platform to interact in a } \\
\text { practical, ethical, and efficient way for everyone who uses it. }\end{array}$ \\
\hline$\# 2$ & $\begin{array}{l}\text { I want to conclude college with high marks and then pursue a master's degree. Then I want to enter the job market and, in } \\
\text { parallel, study and seek information about a public tender that accepts my college degree. In the future, be approved in a public } \\
\text { tender for the Army and pursue a military career. }\end{array}$ \\
\hline$\# 3$ & $\begin{array}{l}\text { In general terms, it is doing something every day with pleasure and using the utmost of my creative abilities and accumulated } \\
\text { experiences and knowledge exponentially, collaborating for research, teaching, and transforming the world for many people. } \\
\text { The essence of success is precisely this union: sharing and absorbing knowledge every day, doing something that really makes } \\
\text { a difference for me and for those who relate to me directly or indirectly. Concretely, my short and medium term goals are to } \\
\text { earn my master's degree, to be able to teach during open hours (at night) and to be able to finish my master's studies and work } \\
\text { at a company. }\end{array}$ \\
\hline$\# 4$ & $\begin{array}{l}\text { Achieve financial independence (get rich on the financial market), study more and work as little as possible (enjoying life } \\
\text { without becoming a slave to work, a jester). I don't want to sell my time working for other people unless it contributes } \\
\text { considerably to my personal development. Never be the jester, the madman who possibly becomes a beggar, not necessarily } \\
\text { some people we see begging in the streets, but in the mental, emotional, and financial sense, with poverty in almost all aspects } \\
\text { of his life, victimized by nature, always passive in the situation that life offers, a believer of predetermination and destiny. }\end{array}$ \\
\hline$\# 5$ & $\begin{array}{l}\text { Being able to finish the Library and Information Science course to better structure myself financially and get enough capital to } \\
\text { open my own business (a small supermarket). Start doing a new undergraduate course in Mathematics. }\end{array}$ \\
\hline$\# 6$ & $\begin{array}{l}\text { Until I am 40, I would like to be in charge of major projects for companies or in my own company where I can create, redefine, } \\
\text { and project new experiences in peoples lives. } \\
\text { There is no specific economic sector like food or clothing, but any one where I can change the way people behave in their spare } \\
\text { time through a new concept, idea, or technological product. }\end{array}$ \\
\hline
\end{tabular}

Table 7. DL and DI of intersection attributes

\begin{tabular}{|c|c|c|c|c|c|c|}
\hline & \multicolumn{4}{|c|}{ Degree of Importance (DI) } & \multirow[b]{2}{*}{ Total } \\
\hline & & $\begin{array}{c}\mathbf{5 0 \%} \\
\text { (3 students) }\end{array}$ & $\begin{array}{c}\mathbf{6 6 . 7 \%} \\
\text { (4 students) }\end{array}$ & $\begin{array}{c}\mathbf{8 3 . 3 \%} \\
\text { (5 students) }\end{array}$ & $\begin{array}{c}\mathbf{1 0 0 \%} \\
\text { (6 students) }\end{array}$ & \\
\hline \multirow{4}{*}{$\begin{array}{c}\text { Degree of } \\
\text { Learning (DL) }\end{array}$} & $\begin{array}{c}\mathbf{5 0 \%} \\
\text { (3 students) } \\
\end{array}$ & --- & $\mathrm{S} 1, \mathrm{~S} 6, \mathrm{~A} 1, \mathrm{~A} 4, \mathrm{~A} 6, \mathrm{~A} 7$ & S2, A5, A8 & --- & 9 \\
\hline & $\begin{array}{c}\mathbf{6 6 . 7 \%} \\
\text { (4 students) }\end{array}$ & --- & $\mathrm{K} 7, \mathrm{~A} 2, \mathrm{~A} 3$ & $\mathrm{~K} 3$ & --- & 4 \\
\hline & $\begin{array}{c}\mathbf{8 3 . 3} \% \\
\text { (5 students) }\end{array}$ & --- & $\mathrm{K} 1, \mathrm{~K} 2, \mathrm{~S} 4, \mathrm{~S} 10$ & K4, K8, K9, S3, S7, S8 & --- & 10 \\
\hline & $\begin{array}{c}\mathbf{1 0 0 \%} \\
\text { (6 students) }\end{array}$ & --- & --- & K5 & --- & 1 \\
\hline \multicolumn{2}{|c|}{ Total } & 0 & 13 & 11 & 0 & 24 \\
\hline
\end{tabular}

(in the same way as it was done here, with DL). In the same way done here, they can seek the connection between the attributes with high DL and the professional success genuinely desired by the students, which represents the DI (of course, as long as the students receive - either from the CI teacher or by other means - the necessary assistance to discover their authentic image of success). Having access to this pathway previously absent from the literature can be of great benefit to CI teachers around the world who wish to offer education aimed at professional success.
This research indicates that CI teaching - all types or just those like the course described here - can leverage professional success, even for those who do not wish to work as CI professionals. Further research will be necessary to fully generalize this conclusion, but to know that this is real even under some circumstances creates good opportunities for teachers and students. In the end, we believe that CI teaching can create a legion of professionals with diverse backgrounds working on different labor markets, who are convinced that CI can benefit them in their pursuit of their own professional success. 


\section{References}

Bensoussan B., Fleisher C.S. (2003) Strategic and Competitive Analysis: Methods and Techniques for Analyzing Business Competition, Upper Saddle River, NJ: Prentice Hall.

Bexon M., Stephens D., Pritchett C. (2002) Competitive intelligence: A career opportunity for the information professional in industry. Journal of Librarianship and Information Science, vol. 34, no 4, pp. 187-196.

Blenkhorn D., Fleisher C. (2003) Teaching CI to three diverse groups: Undergraduates, MBAs and executives. Competitive Intelligence Magazine, vol. 6, no 4, pp. 17-20.

Blenkhorn D., Fleisher C. (2010) Teaching competitive intelligence skills to North American and overseas audiences: A world of difference in pedagogical effectiveness. Journal of Teaching in International Business, vol. 21, no 4, pp. $266-281$.

Calof J.L. (1999) Teaching competitive intelligence: Opportunities and needs. Competitive Intelligence Magazine, vol. 2, no 4, pp. 28-31.

Calof J.L. (2016) Government sponsored competitive intelligence for regional and sectoral economic development: Canadian experiences. Journal of Intelligence Studies in Business, vol. 6, no 1, pp. 48-58.

Dochy F., Segers M., Sluijsmans D. (1999) The use of self-, peer and co assessment in higher education: A review. Studies in Higher Education, vol. 24, no 3, pp. 331-350.

Fleisher C.S. (2004) Competitive intelligence education: Competencies, sources and trends. Information Management Journal, vol. 38, no 2, pp. 56-62.

Fuld L.M. (1995) The New Competitor Intelligence: The Complete Resource for Finding, Analyzing and Using Information About Your Competitors, New York: John Wiley \& Sons.

Gilad B. (2003) CI education Harvard style? Competitive Intelligence Magazine, vol. 6, no 4, pp. 12-16.

Gleason B.L., Peeters M.J., Resman-Targoff B.H., Karr S., McBane S., Kelley K., Thomas T., Denetclaw T.H. (2011) An activelearning strategies primer for achieving ability-based educational outcomes. American Journal of Pharmaceutical Education, vol. 75, no 9, pp. 1-12.

González de Sande J.C., Godino-Llorente J.I. (2014) Peer assessment and self-assessment: Effective learning tools in higher education. International Journal of Engineering Education, vol. 30, no 3, pp. 711-721.

Gutowski N. (2007) Competitive intelligence education: The problem begins in high school. Competitive Intelligence Magazine, vol. 10, no 3, pp. 42-43.

Glitman E.W. (2008) Continuing Education. Competitive Intelligence Magazine, vol. 11, no 5, pp. 48-49.

Horton F.W. (2007) Understanding Information Literacy: A Primer, Paris UNESCO. Available at: https://unesdoc.unesco.org/ ark:/48223/pf0000157020, accessed 21.10.2019.

Hulnick A.S. (2003) Teaching CI in a liberal arts curriculum. Competitive Intelligence Magazine, vol. 6, no 4, pp. $56-57$.

Julien H., Detlor B., Serenko A., Willson R., Lavallee M. (2011) Preparing tomorrow's decision makers: Learning environments and outcomes of information literacy instruction in business schools. Journal of Business \& Finance Librarianship, vol. 16, no 4, pp. 348-367.

Kalb C.C. (2003) Core competencies: A practioner's view. Competitive Intelligence Magazine, vol. 6, no 4, pp. 53-55.

Keiser B.E. (2016) How information literate are you? A self-assessment by students enrolled in a competitive intelligence elective. Journal of Business \& Finance Librarianship, vol. 21, no 3-4, pp. 210-228.

Lantis J., Kille K., Krain M. (2019) Active teaching and learning: The state of the literature. Available at: https://oxfordre.com/ internationalstudies/view/10.1093/acrefore/9780190846626.001.0001/acrefore-9780190846626-e-427, accessed 05.11.2019.

Lemmer C.A. (2015) Using competitive intelligence instruction to develop practice-ready legal professionals. Legal Reference Services Quarterly, vol. 34, no 4, pp. 268-292.

McGonagle J.J. (2007) Training better analysts. Competitive Intelligence Magazine, vol. 10, no 6, pp. 51-52.

Miller J.P. (1994) Educational programs for intelligence professionals. Library Trends, vol. 43, no 2, pp. 253-270.

Miller J.P. (2000) Millennium Intelligence: Understanding and Conducting Competitive Intelligence in the Digital Age, Medford, NJ: Information Today.

Ottonicar S.L.C., Valentim M.L.P., Mosconi E. (2018) A competitive intelligence model based on information literacy: Organizational competitiveness in the context of the 4th industrial revolution. Journal of Intelligence Studies in Business, vol. 8, no 3, pp. 55-65.

Porter M.E. (2008) Competitive Strategy: Techniques for Analyzing Industries and Competitors (with a new introduction), New York: Free Press.

Prescott J.F., Miller S.H. (eds.) (2002) Proven Strategies in Competitive Intelligence: Lessons from the Trenches, New York: John Wiley \& Sons. 
Runtuwene J.P.A., Kenap A.A., Palilingan V.R. (2014) The development of North Sulawesi through competitive intelligence. Journal of Intelligence Studies in Business, vol. 4, no 1, pp. 36-42.

Rychen D.S., Ferrer A.T. (2004) Developing Key Competencies in Education: Some Lessons from International and National Experience, Paris: International Bureau of Education.

Sawka K. (2002) Stages of analysis. Competitive Intelligence Magazine, vol. 5, no 6, pp. 46-47.

Sprent P., Smeeton N.C. (2001) Applied nonparametric statistical methods (3rd ed.), Boca Raton, FL: Chapman \& Hall/CRC.

Strauss A.C., Du Toit A.S.A. (2010) Competitive intelligence skills needed to enhance South Africa's competitiveness. AsLib Proceedings: New Information Perspectives, vol. 62, no 3, pp. 302-320.

Suyin D., Min H., Ying L., Jingyang W., Xiaohong W. (2010) Design of competitive intelligence consciousness and skill cultivating platform for undergraduate students based on SOA and MVC. Paper presented at the 2nd International Workshop on Database Technology and Applications (DBTA2010), 27-28 November, 2010 Wuhan, China.

Tyson K.W.M. (2006) The Complete Guide to Competitive Intelligence (4th ed.), Chicago, IL: Leading Edge Publications.

Zhou Y., Wang Z. (2013) The training strategy of professional core competencies of talents in competitive intelligence. Research Journal of Applied Sciences, Engineering and Technology, vol. 5, no 16, pp. 4088-4093. 